\title{
ANÁLISE DE CURRICULUM VITAE SOB A PERSPECTIVA DA LINGUÍSTICA SISTÊMICO- FUNCIONAL E DA LINGUÍSTICA DE CORPUS
}

Simone Vieira Resende (PUC-SP)

Resumo: Esta pesquisa investiga o Curriculum Vitae (CV) por meio dos pressupostos teóricos da Linguística Sistêmico Funcional (LSF) e da Linguística de Corpus (LC). O contexto discursivo dos CVs é analisado a partir da perspectiva da gramática sistêmico-funcional (HALLIDAY, 1994; HALLIDAY; MATTHIESSEN, 2004). Dentre as diversas possibilidades de investigação, a metafunção ideacional foi escolhida como o recurso linguístico para a análise da relação entre o escritor do CV e seu produto, ou seja, ele mesmo. Por meio das escolhas léxico-gramaticais e da interação entre o escritor e o seu próprio marketing como um produto, investigaremos como o escritor se nomeia e come é nomeado. De que forma esse produto é vendido e que papéis são atribuídos a ele. A LSF que prega a linguagem como interação, a linguagem como uma semiótica social que enfatiza a produção de sentido dentro da cultura e da história. Associada a interface da LSF, a pesquisa faz uso da Linguística de Corpus (LC) por meio da ferramenta de análise: WordSmith Tools (SCOTT, 2012) e da compilação de um corpus de CVs autênticos em língua portuguesa brasileira. A pesquisa aproveita a confluência da LSF com a LC tanto no campo teórico, quanto no metodológico. No teórico, por meio da confluência entre a linguagem e seu uso, no metodológico, por meio da análise de textos. Os resultados mostram que cada um dos contextos discursivos presentes nos CVs possuem uma função própria e que tais funções podem ser observadas por meio das escolhas léxico gramaticais utilizadas especificamente para esse tipo de registro, o que pode proporcionar subsídios para facilitar - o uso da linguagem - a compreensão desse tipo de registro e ajudar tanto o produtor de CVs quanto seus leitores e tradutores.

Palavras-chave: Linguística de Corpus; Curriculum Vitae; Currículo; Linguística Sistêmico-Funcional; Registro.

Abstract: This research investigates Curriculum Vitae (CV) through the theoretical assumptions of Systemic Functional Linguistics (SFL) 
and Corpus Linguistics (CL). The discursive context of CVs is analyzed from the perspective of the systemic-functional grammar (HALLIDAY, 1994; HALLIDAY; MATTHIESSEN, 2004). Among the various research possibilities, the ideational metafunction was chosen as the linguistic resource for the analysis of the relationship between the CV writers and the product produced, that is, the writers themselves. Through lexico-grammar choices and the interaction among writers and their own marketing as a product, we will investigate how writers name themselves and how they are named. How this product is sold and which roles are assigned to them. SFL sees language as interaction, language as a social semiotics that emphasizes the production of meaning within culture and history. Associated with the SFL interface, this research also uses the concepts of Corpus Linguistics $(\mathrm{CL})$ through an analysis tool named: WordSmith Tools (SCOTT, 2012) and the compilation of a corpus of authentic CVs written in Brazilian Portuguese. The research takes advantage of the confluence between SFL and $\mathrm{CL}$, since both belong to the same theoretical and methodological fields. In the theoretical field, the link between SFL and LC can be seen through the confluence between language and its use, in the methodological field, it is seen through the text analysis. The results show that each of the discursive contexts present in the CVs have their own function and that such functions can be observed through the lexicographic choices used specifically in this type of register, which may provide subsidies to facilitate - language use - the understanding of this kind of register and help both the CV producer, readers and translators.

Keywords: Corpus Linguistics; Curriculum Vitae; Curriculum; SystemicFunctional Linguistics; Register.

\section{INTRODUÇÃO}

O objetivo desse estudo é investigar os padrões léxicogramaticais dos Curriculum Vitae através dos pressupostos teóricos da Linguística Sistêmico-funcional (LSF). Para Halliday (1994), a LSF investiga o uso da língua dentro do contexto social e reconhece que a linguagem está viva e 
presente nas situações sociais e, portanto, sofre influência delas. Essa abordagem foi escolhida devido a sua base sistêmica que possibilita a análise do indivíduo dentro de um contexto social, uma vez que a LSF caracteriza a língua como um fenômeno social e interpreta a língua como um sistema modelador de realidade. Esse aspecto social possui profundo relacionamento com o propósito dos CVs, uma vez que esse tipo de registro leva o contexto situacional em consideração.

O corpus de investigação desse trabalho é formado por currículos autênticos, escritos em língua portuguesa e coletados a partir de inúmeras fontes diferentes, dentre elas, o site do LinkedIn, a Plataforma Lattes, o Banco de Currículos e alguns CVs acumulados através de pesquisas online, doações de amigos e compilados com a ajuda do departamento de Recursos Humanos (RH) de empresas amigas. A seleção foi feita seguindo o critério de que quanto mais Cvs, mais representativo o corpus ficaria. Os Cvs foram separados por tipos: empresariais e acadêmicos, por gênero: feminino e masculino e por origem: português brasileiro e português europeu.

Consideramos para essa pesquisa a classificação do CV como um tipo de registro. A utilização do termo registro não é equivalente ao que se entende por gênero, não no que se 
refere a linha teórica escolhida, a LSF. Dentro dos pressupostos da LSF, o gênero e o registro designam ideias diferentes. 0 registro refere-se ao que acontece no contexto situacional e o gênero refere-se ao contexto cultural. O gênero nesse caso da LSF não equivale ao feminino e masculino e tampouco ao gênero literário como romance ou suspense. Mas, sim ao que Halliday chama de contexto de cultura e, portanto, aquele que leva o macro contexto em consideração, ou seja, um contexto mais estável e mais abrangente do que o contexto de situação. Como esse estudo analisa os padrões léxico-gramaticais presentes no $\mathrm{CV}$, consideramos mais adequado para esse recorte a definição do CV como sendo um registro. Nas palavras de Fuzer e Cabral (2014, p.25), o registro é a configuração de significados que acontece por causa da situação.

A compilação e análise dos dados são baseadas nas teorias e ferramentas da Linguística de Corpus (BERBER SARDINHA, 2004) e da linguística Sistêmico-Funcional (HALLIDAY; MATTHIESSEN, 2004; THOMPSON, 2004). Dentre as diversas possibilidades de investigação, objetivou-se analisar especificamente o uso da primeira pessoa do singular (EU) com base na teoria do Sistema de Transitividade da Linguística Sistêmico-Funcional. A função ideacional 
foi escolhida como o recurso linguístico para a análise da relação entre o escritor do CV e seu produto, ou seja, ele mesmo. Essa escolha se deve ao desejo de especificar apenas um item para a investigação, o aspecto verbal e de não fugir dos objetivos dessa descrição. Um trabalho mais longo e aprofundado sobre todas as metafunções fugiria dos objetivos de um trabalho dessa proporção. Essa investigação leva em consideração as escolhas léxico-gramaticais, assim como a interação entre o escritor e o marketing dele mesmo como um produto. Investigamos como o escritor se nomeia e come ele é nomeado, como esse produto é vendido e que papéis são atribuídos a ele. As unidades fraseológicas analisadas foram escolhidas de acordo com as desinências do verbo conjugado na primeira pessoa. Cada ocorrência foi tabulada em todo o corpus e analisada com a ajuda do programa WordSmith Tools (SCOTT, 2012).

Tanto a LSF como a LC têm pontos de inter-relações que podem contribuir de maneira significante para as análises dos CVS. Ambas apresentam aspectos em comum sob a perspectiva sistêmica da linguagem. As duas pressupõem sistemas linguísticos paradigmáticos com base na probabilidade (HALLIDAY, 1993, p.3). Sendo assim, tornase possível compreender os dados e suas nuances através 
das instanciações do sistema que são refletidas nos textos através dos padrões léxico-gramaticais neles presentes.

Essa investigação se divide em três etapas distintas, a primeira trata da descrição e definição do que é a LSF e como ela contribui para uma pesquisa dessa natureza. A segunda parte descreve a Linguística de Corpus e consequentemente como o corpus de CVs foi compilado e organizado e junto com a LSF dão suporte metodológico para as análises da pesquisa. A última e mais nuclear das seções, trata da análise dos dados, ou seja, a análise das unidades léxico-gramaticais extraídas do corpus e das conclusões e pressupostos formados pela associação desses padrões aos conceitos da LSF, mais especificamente em relação a metafunção ideacional analisada em cada um dos padrões extraídos dos CVs.

A compilação do corpus está em andamento e apenas uma parte dele foi usada neste estudo. Portanto, apenas as estruturas verbais dos enunciados são consideradas para este trabalho. O trabalho se encerra com as considerações finais e conclusões sobre a transitividade presente nos CVs e com considerações a respeito das possíveis pesquisas que ainda podem ser feitas no campo dos CVs, tendo como base a LSF, a LC os Estudos da Tradução. 


\section{A LINGUÍSTICA SISTÊMICO-FUNCIONAL}

A LSF é um modelo de análise linguística usado para descrever a linguagem. É possível entender a Linguística Sistêmico-Funcional (LSF) como sendo uma teoria geral do funcionamento da linguagem humana que pode ser concebida com uma premissa descritiva do uso linguístico. Ela foi criada por Michael Halliday e amplamente divulgada por volta dos anos 80. Em outras palavras, ela é uma teoria de descrição gramatical coerente que oferece uma descrição plausível dos motivos pelos quais uma língua pode variar em função do seu grupo de falantes e do seu contexto de uso. Além dessa característica singular de descrever a gramática e oferecer instrumentos de descrição, a LSF também oferece metalinguagem e técnicas que são muito úteis para análises textuais.

No caso da análise dos CVs, o modelo da LSF pode ser muito útil, já que ele proporciona uma oportunidade de ir além do mero reconhecimento e classificação gramatical das características desse tipo de texto. A LSF é sistêmica porque vê a gramática como um sistema de escolhas potenciais e não-arbitrariamente motivadas. Ela é também funcional porque procura explicar as implicações comunicativas de uma seleção dentro de um desses sistemas. Dessa forma, podemos não apenas descrever o 
CVs, mas também analisar suas funções linguísticas. Um aspecto relevante da LSF é o fato de que ela determina que os componentes essenciais do significado na língua são componentes funcionais, ou seja, nós somos capazes de perceber que a língua que usamos varia de acordo com diversas situações de interação da nossa vida social e a preparação de um CV é uma delas. Ikeda, et al. (2015, p.228) apresentam uma definição da LSF que ajuda a compreender os motivos de seu uso nesse estudo. Para eles a LSF é uma proposta teórico-metodológica na qual a língua está estruturada para construir simultaneamente três tipos de significados, também chamados de metafunções: a Ideacional, a Interpessoal e a Textual, que estudaremos mais à frente. Para eles, essa simultaneidade semântica decorre do fato de a língua ser um sistema semiótico, um código convencionado, organizado como um conjunto de escolhas no nível intermediário de codificação, a léxicogramática. A partir do momento que esse conhecimento intuitivo é colocado em prática, passamos a entender que o contexto influencia nossas escolhas, fazemos assim um uso funcional da linguagem.

A LSF pode ajudar a descobrir e entender como e se os CVs conseguem ou não expressar seus significados através 
das potencialidades da língua. Essa contribuição pode ser feita e investigada através da análise textual dos padrões semânticos surgidos da necessidade do indivíduo de relatar suas conquistas, sua formação e experiência ao mesmo tempo que interpreta suas ações e as compartilha com os outros. Dessa forma, essa investigação se preocupa em olhar para os CVs de uma forma real e funcional, levando em conta a sua aplicabilidade social, sem a ideia pré-concebida do CV ideal e sem julgamento de valor de como ele deve ou não deve ser e sim de como ele é.

Seguindo essa prerrogativa social da LSF, vamos analisar os CVs como sendo uma unidade semântica que apresenta seus significados nas orações que os compõem. Não se trata de uma mera análise das classes gramaticais, longe disso. Uma investigação com base na LSF classifica a gramática em categorias que ajudam o linguista a refletir sobre os padrões semânticos que estão sendo investigados. Esse tipo de análise leva os aspectos exteriores ao texto em consideração, assim como todo o universo, os significados e o contexto não linguístico do indivíduo que produz o CV. Halliday (1994) sugere que o texto seja o ponto de partida para o entendimento de como usamos a língua para fazer e conseguir coisas. Ele postula que o texto se desenvolve 
e adquire sentido dentro de dois contextos: o cultural e o situacional. Dentro do contexto de situação há três fatores que vão determinar as escolhas linguísticas: o campo, relações e modo.

O campo pode ser entendido como "a atividade que está sendo realizada pelos participantes, à natureza da ação social que está ocorrendo, com objetivo específico" (FUZER; CABRAL, 2014, p.30). No caso dos CVs, de forma recorrente, o campo remete à propaganda que o indivíduo faz das suas conquistas pessoais e o relato das suas experiências e formação. A finalidade é fazer uma apresentação pessoal com o objetivo de convencer o leitor a lhe dar um trabalho. O objetivo é conseguir um emprego.

A segunda variável do contexto situacional é a relação. Ela descreve os participantes envolvidos na situação. Aqueles que falam ou escrevem e aqueles que ouvem ou leem. No caso dos CVs, o esperado é que os participantes sejam o escritor do CV, aquele que apresenta suas experiências e conquistas e o leitor, o possível empregador ou recruta. Segundo as autoras Fuzer e Cabral:

As relações envolvem os participantes, a natureza dos papeis que desempenham, o grau de controle de um participante sobre o outro, a relação entre eles (hierárquica ou não) e a distância social 
ou o grau de formalidade (mínima, média ou máxima, dependendo da frequência com que interagem. (2014, p.30)

As três expressões destacadas na citação resumem os pontos principais dessa variável. Nos CVS, a relação é estabelecida entre dois participantes: o candidato e o recruta. O grau de envolvimento entre eles não é estabelecido no texto, porém é claro que o enunciador do CV é o candidato que se apresenta e produz o texto e o destinatário são os recrutas e empregadores das empresas onde o CV será analisado. A distância social, que na citação é descrita como sendo mínima, média ou máxima, no caso dos CVs é máxima.

A terceira e última variável situacional é o modo. Ele pode ser definido como o veículo utilizado naquela situação. Para Fuzer e Cabral (2014, p.30), o modo refere-se à função que a linguagem exerce. Em outras palavras, ele se refere ao que os participantes esperam que a linguagem faça por eles, ou seja, trata do papel da linguagem que pode ser, constitutivo, auxiliar ou suplementar. O meio de compartilhamento entre os participantes, que pode ser um diálogo ou um monólogo. O canal pode ser escrito, grafado, fônico ou visual. Nos CVs, o modo é o escrito. A linguagem é muitas vezes verbal e não verbal. No caso do verbal escrito, a linguagem é constitutiva e organizada de modo expositivo. Como por exemplo: 
"graduado em letras pela PUC-SP". No caso do não verbal, a organização da apresentação como a escolha das fontes e cores e o layout do arquivo mostram o quanto o candidato se preocupa com detalhes.

As três variáveis apresentadas aqui ajudam o pesquisador a identificar aspectos do contexto de situação dos CVs a partir de determinadas palavras e estruturas léxicogramaticais específicas e recorrentes desse tipo de registro. Isso é possível porque as três variáveis contextuais apresentadas anteriormente (campo, relação e modo) estão intrinsecamente relacionadas às funções que a linguagem desempenha (FUZER; CABRAL, 2014, p.32).

Halliday (1994) chama essas funções de METAFUNÇÕES e as define como sendo as manifestações dos propósitos de uso da língua: entender o meio, que seria a metafunção ideacional, relacionar-se com outros, o que ele chama de metafunção interpessoal e por último, organizar a informação, a chamada metafunção textual.

Nos CVs, analisamos as metafunções a partir da observação das orações, uma vez que, com base nessas três metafunções, podemos entender a oração como sendo uma unidade gramatical plurifuncional. Ou seja, ela é organizada de acordo com os significados ideacionais, interpessoais, que 
pode ser entendida e identificada por um sistema próprio de camadas léxico-gramaticais. Para entender melhor como se pode identificar essas características léxico-gramaticais nos CVs e a partir dessa identificação estruturar, investigar e entender como o registro é construído temos que nos aprofundar um pouco mais na questão das metafunções.

Como já mencionado no início do texto, a LSF postula que todas as línguas se organizam em tipos fundamentais de significados ou componentes, dessa forma, ela vê o texto como um produto da linguagem que simultaneamente desempenha três metafunções nos discursos: a função Ideacional, a Interpessoal e a Textual. Em outras palavras, a LSF apresenta a linguagem como meta funcional, uma semiótica social que é usada pelos indivíduos de três formas diferentes, ou seja, com três propósitos diferentes que os leva a atingir três funções diferentes:

- A função ideacional ou reflexiva: ela manifesta a intenção de compreender o ambiente. O indivíduo fala das experiências externas e internas do mundo ao seu redor. Essa função também pode ser chamada de experiencial, correspondendo ao que podemos chamar de organização lógica de conteúdos e eventos, ou seja, a forma como estruturamos nossa experiência do mundo 
sem deixar de servir a representação. Usamos essa função para codificar a nossa vivência. Ela nos fornece imagens da realidade física e mental e nos ajuda a codificar significados da nossa experiência, codificar significados ideacionais. No caso dos CVs, é a oração o meio pelo qual a linguagem vai materializar essas experiências e processos e uma análise dos verbos torna possível um esboço dessa realidade. Halliday ressalta haver três tipos principais de processos e três tipos secundários. Os principais são os materiais, mentais e relacionais e os secundários são os verbais, comportamentais e existenciais. Observe a relação entre esses elementos na figura abaixo:

\begin{tabular}{|l|l|l|}
\hline Contexto & Metafunção & Sistema \\
\hline campo & ideacional & transitividade \\
\hline
\end{tabular}

Figura 1. Esquema de relação entre o contexto, a função e o sistema

- A função interpessoal ou ativa: ela manifesta a intenção de agir com outros no ambiente, estabelece relações interpessoais na sociedade. Usamos essa função para codificar nossas interações e para nos posicionarmos e demonstrar esse posicionamento através dos nossos enunciados. Diferente da função anterior que nos ajuda a codificar nossas experiências, a função interpessoal nos ajudar a codificar nossas atitudes, 
nossas relações sociais e interações com os demais indivíduos. As relações expressas por essa metafunção vão corresponder a natureza dos indivíduos, suas posições, seus papéis e status e a forma como eles se relacionam, nesse caso o candidato a uma vaga, o chefe, o empregado, o entrevistador, o ouvinte, o falante.

\begin{tabular}{|l|l|l|}
\hline Contexto & Metafunção & Sistema \\
\hline relações & interpessoal & modo \\
\hline
\end{tabular}

Figura 2. Esquema de relação entre o contexto, a função e o sistema

- A função textual: ela é uma combinação das duas funções anteriores, já que tem a função de ajudar o indivíduo a organizar a mensagem para que seja compreendida pelos seus pares, permitindo que o indivíduo aja e crie sentido nos diversos estratos da sociedade. Nós usamos essa função para organizar os significados construídos nas duas funções anteriores. A metafunção textual organiza os nossos significados ideacionais e interpessoais de uma forma coerente e linear através do desenvolvimento textual e da organização retórica. Essa função deixa a mensagem reconhecível para quem a recebe, no caso dos CVs, não se investiga apenas a relação entre as frases, mas também como cada oração se organiza internamente e que significado ela carrega. De acordo com Halliday (1994), a estrutura da oração caracteriza 
um evento comunicativo, esse elemento é chamado de tema e o restante da oração é chamado de rema. O tema é o ponto de partida da oração.

\begin{tabular}{|l|l|l|}
\hline Contexto & Metafunção & Sistema \\
\hline modo & textual & tema e rema \\
\hline
\end{tabular}

Figura 3. Esquema de relação entre o contexto, a função e o sistema

Os três elementos do contexto mencionados anteriormente - campo, relações e modo, - formam a configuração do contexto situacional, esses elementos determinam as escolhas linguísticas que vão criar os diferentes significados. Para investigar os CVs, vamos nos concentrar na primeira função descrita por Halliday, a função ideacional, pelo simples fato dela abranger duas funções distintas e fundamentas nesse tipo de registro: a função experiencial e a função lógica. Ambas podendo ser analisadas na oração através do sistema de transitividade. A meu ver, o contexto de situação do CVs que vai abranger o conceito de registro e suas variáveis de campo, relação e modo são descrições essenciais para se compreender por inteiro esse tipo de documento sem deixar as questões culturais de lado. Se levarmos em consideração o questionamento de Halliday quando perguntou: "Por que a língua é como é?" Vamos perceber que a natureza da língua é ligada às necessidades que impomos e às funções que deve servir. Segundo Halliday, "nos casos mais concretos 
essas funções são especiais de uma cultura," podendo não ter paralelo em uma outra sociedade (1970, p.141). O que queremos ressaltar é a importância de considerar aspectos diferentes para a descrição linguística de um registro. Em outras palavras, nem uma descrição extrínseca das estruturas linguísticas dos CVs, nem uma descrição puramente linguística que não leve em consideração as necessidades que os indivíduos impõem às línguas, vão conseguir chegar a resultados satisfatórios em relação ao CVs pelo simples fato de não considerar a realidade em sua totalidade.

Dessa forma, as expressões léxico-gramaticais encontradas nos CVs são determinadas pelos usos a que as sujeitamos, isso significa que, os significados que queremos "fazer" ou transmitir nos ajudam a configurar os recursos linguísticos. Porém, os significados que "podemos querer fazer" são totalmente dependentes de aspectos contextuais. Apesar de considerar a metafunção textual como uma das mais adequadas para esse tipo de investigação, não apenas por abranger as duas metafunções anteriores, mas também por demandar uma característica semântica fundamental de análise, uma vez que o linguística consegue apontar quais são as identificações entre o que o escritor do CV tem em mente quando produz seu enunciado e com o que ele se identifica, em outras palavras, a identificação de tema e rema pode ajudar 
a descrever a forma que o enunciador realmente constrói sua imagem, resolvemos concentrar nossa análise apenas na metafunção ideacional. Uma análise mais profunda de tema e rema que considere todas as questões pronominais foge do escopo desse trabalho final, sendo assim, apenas a questão verbal e as transitividades são levadas em conta.

A próxima seção trata das definições da Linguística de Corpus e das ferramentas utilizadas para selecionar as orações e os verbos da pesquisa com CVs.

\section{A LINGUÍSTICA DE CORPUS E A LINGUÍSTICA SISTÊMICO- FUNCIONAL}

Segundo Berber Sardinha (2009, p.7), “a Linguística de Corpus é um campo que se dedica à criação e análise de corpora (plural latim de corpus) que são conjuntos de textos e transcrições de fala armazenadas em arquivos de computador". De acordo com o autor a LC vem mudando a maneira como se investiga a linguagem, nos seus mais diversos níveis, colocando à disposição do analista, quantidades de dados antes inacessíveis. Por essa razão, escolhemos a LC como ferramenta metodológica para esse trabalho final, uma vez que poderemos criar lista de verbos e orações de forma automática com a ajuda do WordSmith Tool ${ }^{1}$.

1 Para mais informações sobre o WordSmith Tool consultar o site http://www.lexically.net/ wordsmith/. 
Berber Sardinha (2009, p.8) descreve o WordSmith Tool como sendo mais do que um simples programa, ele é um conjunto de programas integrados e destinados à análise linguística, que permite fazer análises baseadas na frequência, ocorrência e co-ocorrência das palavras nos corpora. O programa foi escolhido devido a facilidade de uso e variedade de ferramentas.

Além da ajuda metodológica na compilação e organização dos dados, a LC também possuiu outros aspectos relevantes e similares a LSF usados nessa pesquisa. É possível conceber uma complementaridade entre a Linguística de Corpus e a abordagem sistêmico-funcional, uma vez que ambas as vertentes concebem a linguagem enquanto fenômeno social, em função de seu uso e sua funcionalidade no discurso. Uma das características da LC como uma vertente que tem um olhar diferente sobre a linguagem (TEUBERT; ČERMÁKOVÁ, 2007, p.35) está relacionada à concepção de que a língua é um fenômeno social, o que difere significantemente das concepções mais formalistas da linguagem. Uma vez que a língua é concebida como um fenômeno social, à LC interessa investigar como significados são construídos e como podem ser verbalmente comunicados e socialmente estabelecidos pelos indivíduos na sociedade. Dessa forma, um dos 
interesses da LC é verificar de que forma palavras, sentenças e textos ganham significados em função dos diferentes contextos em que se encontram. Sendo assim, a linguagem é analisada através do texto, que está relacionado à própria concepção da palavra corpus.

Tendo traçado a ligação entre a LSF e a LC, podemos passar para os aspectos da LC, mais especificamente o uso do programa WordSmith Tools, que pode contribui para nossa investigação dos CVs. Conforme explicado na introdução, escolhemos nomear os CVs como sendo um tipo de registro. Acreditamos que, como diz Halliday, o texto é um produto do seu entorno e funciona nele. Ele possui uma estrutura genérica e pode mostrar padrões de relação com a situação. Em outras palavras, a situação vai determinar que certas escolhas e determinadas seleções sejam feitas no sistema linguístico. Não se trata apenas de analisar o vocabulário ou a terminologia escolhida per se. Mas, sim de analisar a relação entre o que cada situação determina, ou seja, as escolhas feitas a partir das determinações estabelecidas por cada uma das situações. Pensar no CV como sendo um registro é vê-lo além das escolhas como: o texto tem características formais e informais ou planejadas e espontâneas. Por fim, manter em mente que o CV é um tipo de registro que acomoda diversos 
tipos de traços linguísticos e que pode ser descrito a partir das suas características léxico-gramaticais e principalmente funcionais. Vale ressaltar que entre as várias linhas teóricas que definem os gêneros e os registros há muitas diferenças e muitas semelhanças. Um ponto em comum entre elas é o fato deles se relacionarem com a vida e com a sociedade e os CVs não fogem dessa premissa.

\section{O CORPUS DE CVS}

O Corpus utilizado para essa investigação é formado por 400 CVs escritos em Português do Brasil e compilados a partir da plataforma LinkedIn, a plataforma Lattes e bancos de dados pessoais e de empresas de $\mathrm{RH}$. Os CVs pertencem a homens e mulheres entre 18 e 60 anos e com formações diferentes, tanto da área empresarial, como da área acadêmica. O corpus está em fase de planejamento e os CVs ainda estão sendo coletados. O plano inicial é coletar cerca de dois mil CVs em língua portuguesa. Até o presente, o corpus tem a constituição apresentada na figura 4, sendo duzentos (200) CVs acadêmicos coletados direto da Plataforma Lattes, 100 de pesquisadores femininos e 100 masculinos e mais duzentos (200) CVs empresariais, também divididos em gênero masculino e feminino. A sigla CVAPORTBRM usada na figura 4 representa que os currículos armazenados nessa 
categoria são currículos acadêmicos (Lattes), do português do Brasil, masculinos, ou seja, pertencem a um indivíduo do gênero masculino. Os CVAPORTBRF, pertencem ao gênero feminino. Por sua vez, os CVEPORTBRM referem-se aos CVs empresariais (LinkedIn), do português do Brasil, do gênero masculino e os CVEPORTBRF são os do gênero masculino.

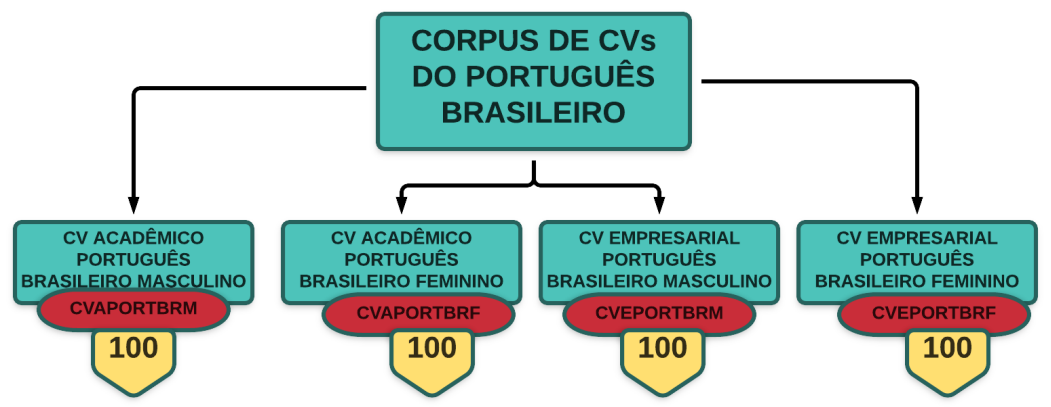

Figura 4: O Corpus de CVs do Português

A escolha do CV como corpus de investigação se deve ao fato de haver poucas fontes de pesquisa linguística aplicada a respeito desse registro. Inúmeras são as fontes de pesquisa na área dos Recursos Humanos e gênero que apresentam templates de como o CV deve ser escrito, como os trabalhos de Bathia, 1993; Swales, 1990 e até os mais recentes como os de Seely, 2005 e Davis, 2003. Alguns trabalhos, como o de Furka, 2008, consideram o aspecto cultural do CV, ou seja, aceita e investiga o fato de que esse tipo de texto é condicionado culturalmente, o que por si só já justifica uma investigação desse tipo. 
O termo Curriculum Vitae tem origem no latim. A palavra Curriculum significa percurso em português e Vitae quer dizer vida. Sendo assim, um Curriculum Vitae descreve o percurso da vida de um indivíduo.

O Vocabulário ortográfico da Língua Portuguesa (VOLP) ${ }^{2}$ apresenta os termos currículo e curriculum como possíveis em língua portuguesa, os dois como substantivos masculinos, o último de língua estrangeira. Em língua portuguesa o termo mais utilizado é currículo e não curriculum. De acordo com o Corpus do Português ${ }^{3}$, formado por textos em português europeu e português do Brasil, o termo currículo é quase cinco vezes mais usado do que curriculum. O mesmo acontece no corpus de referência, o CB, Corpus Brasileiro ${ }^{4}$, um corpus contemporâneo do Português Brasileiro formado por mais de um bilhão de palavras, o número de ocorrências do termo currículo em comparação com curriculum é bem mais alto. Essa informação, mesmo parecendo óbvia e irrelevante, pode ser de extrema importância para o tradutor, na hora de fazer escolhas ou de justificativas a respeito do seu fazer tradutório. A estratégia de verificar o número de ocorrências

2 Mais informações em: http://www.academia.org.br/nossa-lingua/busca-no-vocabulario.

3 Corpus do Português. Davies, Mark and Michael Ferreira. (2006) Corpus do Português: 45 million words, 1300s-1900s. Disponível em: http://www.corpusdoportugues.org. Acesso em: 15.jan.2016.

4 CB - Corpus Brasileiro. Compilado pela equipe do prof. Dr. Tony Berber Sardinha e disponível em: http://corpusbrasileiro.pucsp.br/x/. Acesso em: 15.jan.2016. 
de um termo específico em um determinado corpus permite que o tradutor estenda a sua busca para além do dicionário. Essa atitude pode ajudar a garantir uma autonomia nas descobertas e investigações e pode ser útil tanto para os tradutores iniciantes quanto para os já experientes.

Veja abaixo os quadros com o resultado das pesquisas feitas sobre os termos currículo e curriculum Vitae nos dois corpora, o Corpus do Português e o Corpus Brasileiro - CB:

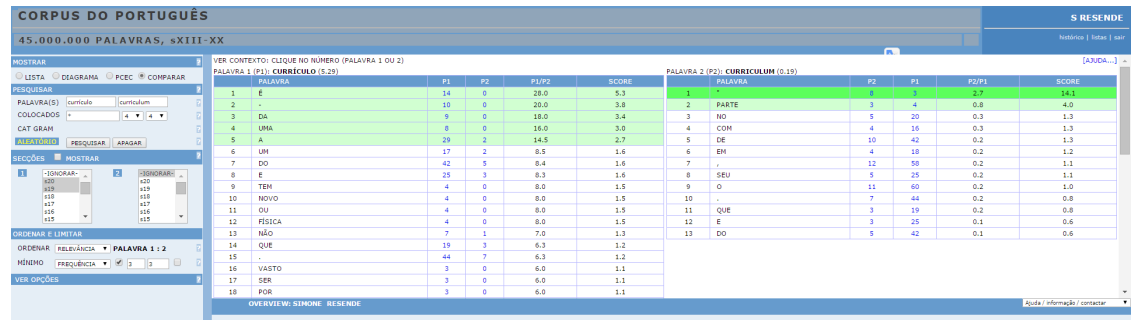

Figura 5. 0 termo Currículo vs. Curriculum Vitae no Corpus do Português

Pode-se notar que o número de ocorrências entre um termo e outro é quase seis vezes maior. O mesmo acontece no corpus contemporâneo do Português Brasileiro como mostra as três etapas da figura 6 . O número de ocorrência diminui muito quando se trata do termo Curriculum Vitae. Em ambos os casos, a pesquisa também revelou que os termos investigados são geralmente acompanhados do substantivo curso, o que nos leva a pensar que grande parte de ocorrência do termo currículo, na verdade se refere a estrutura de curso e não ao percurso e descrição 
da vida de um indivíduo. Contudo, esse tipo de investigação também serve para revelar qual seria o equivalente desse termo em língua inglesa, se a investigação fosse feita em corpora da língua inglesa dos Estados Unidos da Europa. Porém, uma investigação desse porte foge ao escopo desse trabalho.
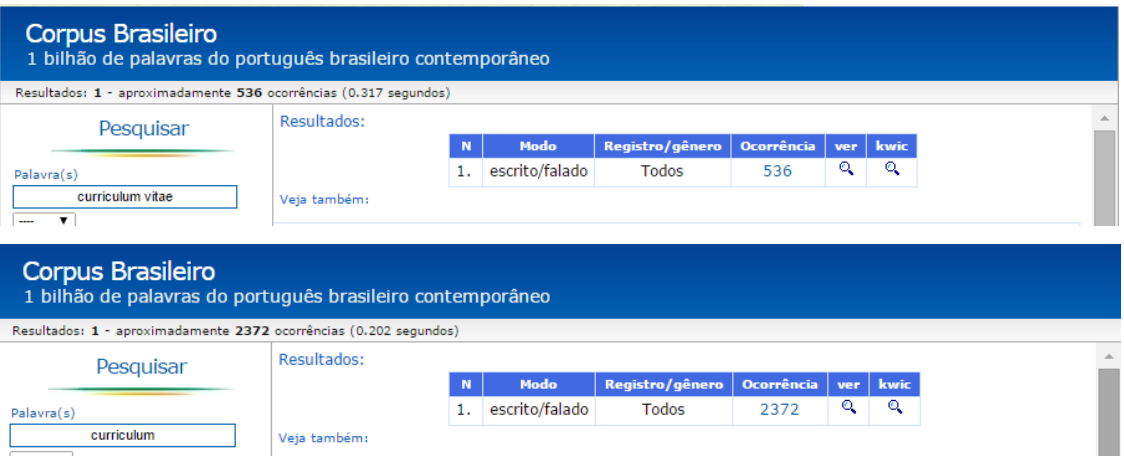

Corpus Brasileiro

1 bilhão de palavras do português brasileiro contemporâneo
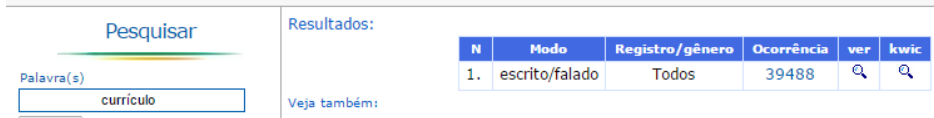

Figura 6. 0 termo Currículo vs. Curriculum Vitae no Corpus Brasileiro (CB)

A figura 6 corrobora a afirmação de que o termo currículo é o mais adequado para a grafia em português do Brasil e, portanto, servirá de base para a continuidade desse estudo. Essa pesquisa, apesar de preliminar e incipiente com apenas 400 CVs em língua portuguesa, abre uma dimensão para muitas investigações que vão além dos aspectos culturais e 
os propostos comunicativos, podendo alcançar as questões da tradução, análises do discurso narcisista, criação de imagem e marca, entre outras.

\section{ANÁLISE E DESCRIÇÃO DOS DADOS}

De acordo com as definições de metafunções apresentadas na segunda parte desse trabalho, Halliday (1994) postula que uma oração é o meio pelo qual a linguagem expressa de forma concreta os processos que controlam e denotam a realidade. Segundo ele, uma oração pode expressar três tipos de significados representados por três diferentes funções: a metafunção interpessoal refere-se a característica da linguagem de estabelecer trocas entre os indivíduos, a metafunção textual organiza a mensagem de forma lógica e a metafunção ideacional, escolhida como foco desse trabalho, refere-se a característica da linguagem de falar sobre o mundo e as experiências.

Seguindo a recomendação da Profa. Dra. Leila Bárbara, da Pontifícia Universidade Católica de São Paulo, o melhor caminho para iniciar uma investigação linguística é pelos verbos. Segundo a professora Leila, quando você não sabe como começar uma investigação, comece pelos verbos. Tudo o que você precisa saber os verbos vão dizer. Sendo assim, resolvemos seguir essa dica e nos concentrar nesse recorte. 
Obviamente, a professora não ressalta a importância dos verbos aleatoriamente. Para Halliday \& Matthiessen (2004), a experiência de um indivíduo é entendida como um fluxo de acontecimentos e situações que se materializam através de processos. Esses processos são na sua maioria representados por verbos. Tais processos são constituídos por indivíduos, os participantes da situação, e por situações adjacentes de modo, espaço e tempo que completam o processo. Esses processos são identificados por Halliday como sendo Materiais, Mentais e Relacionais e estão representados nos verbos que servem como base gramatical para a teoria da experiência. Cada um desses processos pode ser identificado pelos verbos se partirmos da premissa que são eles que representam as experiências humanas. Há ainda mais três classificações secundárias dos processos, e Halliday os chama de Verbais, Comportamentais e Existenciais. Vale ressaltar que não há hierarquia entre os processos, e os limites de divisão entre eles é muito tênue. O mundo da experiência é indeterminado e obscuro e pode ser representado de muitas formas diferentes, os processos apresentados por Halliday contribuem de forma distinta para construir e registrar esse mundo de experiências. Sabemos que cada língua representa as experiências de uma forma diferente, porém, segundo Halliday, o processo é sempre o elemento mais central e 
os indivíduos, os participantes que estão envolvidos nele. Há sempre um processo, um ou mais participantes e uma circunstância. Na grande maioria das vezes, os processos são realizados por grupos verbais e podem ser localizados no tempo, e os participantes são identificados pelos grupos nominais. As circunstâncias podem ser identificadas pelos grupos adverbiais e sintagmas preposicionais. Não há espaço nessa pesquisa para descrever e considerar todos os processos, participantes e circunstâncias profundamente, passaremos à aplicação dos conceitos na investigação das orações do corpus levando em consideração apenas os grupos verbais (destaque em amarelo nas figuras). Contudo, para que a análise não tenda a vagar pelo caminho da subjetividade, vamos fazer um resumo do contexto situacional dos $400 \mathrm{CVs}$ analisados:

Campo: as experiências de trabalho, de aprendizagem e de vida de um indivíduo.

Relação: o candidato a uma vaga e o empregador.

Modo: os CVs são constituídos predominantemente do modo argumentativo fundido com a narrativa e a descrição.

Essa pequena descrição ajuda a entender o contexto dos CVs e a escolha da metafunção experiencial (ideacional) como base para a nossa análise. Acreditamos que quando 
o indivíduo expressa sua experiência do mundo material (trabalhando ou estudando) ou do seu mundo interior (sua consciência), ele está utilizando o componente experencial da metafunção ideacional da linguagem (FUZER; CABRAL, 2014 , p.39) e isso acontece o tempo todo nos CVs, uma vez que é por meio dele que o indivíduo relata suas experiências. Quais são os aspectos léxico-gramaticais dos CVs capazes de representar essas experiências do indivíduo? Escolhemos os verbos mais frequentes nos CVs para nos ajudar nessa descrição. Para isso vamos relembrar o papel de cada elemento da oração através da visualização da figura a seguir e da listagem dos verbos que ocorrem nos CVs conforme as figuras que seguem.

Cabe lembrar que apesar de termos escolhido analisar os verbos, nós sabemos que sistema de transitividade da oração afeta não apenas o verbo, mas também os participantes e as circunstâncias. No caso do CV o ator do processo é sempre o EU, o candidato à vaga e a circunstância, ou seja, a meta, é na sua maioria representada pelo empregador, ou a agência responsável pela colocação desse ator no mercado de trabalho. Verificamos que nos CVs, alguns verbos como TRABALHAR, ADQUIRIR e TER estavam algumas vezes envolvidos em situações um pouco distintas 
das já descritas e o que antes chamávamos de ator passa a ser experienciador e o que chamamos de circunstância (o empregador) passa a ser um fenômeno, como por exemplo uma experiência de vida, de escola ou de trabalho. Foi possível verificar nas orações dos CVs que algumas vezes o ator, o eu do CV, não ocupava necessariamente a posição de sujeito da frase ou não estava explícito na oração. Entendemos essa estratégia de passividade como uma tentativa de distanciar o EU do objeto que se está vendendo no CV, o próprio ator. Esse distanciamento faz parte da transformação desse ator em um objeto que está sendo ofertado e descrito no texto. As estruturas passivas proporcionam essa situação. Observe os exemplos de cada umas das situações descritas:

1. O ator + processo material + meta $=$ Trabalhou na Petrobrás.

2. $\mathrm{O}$ ator + processo material + circunstância $=$ Graduou-se em letras.

3. Processo material + circunstância $=$ Foi aprovado em concurso público em 2011.

\section{Oração}

\begin{tabular}{|l|l|l|}
\hline Participante (a) & Processo (b) & Circunstância (c) \\
\hline Grupo nominal & Grupo verbal & Grupo adverbial \\
\hline
\end{tabular}

Figura 7. Elementos experienciais da oração (relação típica em português) 


\begin{tabular}{|c|c|c|}
\hline Processo Material & Processo Mental & Processo relacional \\
\hline $\begin{array}{l}\text { Derivam da } \\
\text { consciência e } \\
\text { da percepção } \\
\text { externa. Observar } \\
\text { os outros e ver o } \\
\text { que eles fazem. }\end{array}$ & $\begin{array}{l}\text { Derivam da } \\
\text { consciência e da } \\
\text { percepção interna. } \\
\text { Observar nós mesmos, } \\
\text { o que sentimos e como } \\
\text { reagimos. }\end{array}$ & $\begin{array}{l}\text { Generalizar e relacionar } \\
\text { as experiências. } \\
\text { Observar os outros } \\
\text { e nós e relacionar as } \\
\text { observações. }\end{array}$ \\
\hline $\begin{array}{l}\text { adquirir, } \\
\text { trabalhar, } \\
\text { procurar, realizar, } \\
\text { capacitar, graduar, } \\
\text { aprovar }\end{array}$ & $\begin{array}{l}\text { valorizar, pretender, } \\
\text { gostar, querer }\end{array}$ & $\begin{array}{l}\text { ter, ser, motivar, } \\
\text { inspirar, possuir }\end{array}$ \\
\hline
\end{tabular}

Figura 8. Esquema dos Processos e Categorias Gramaticais (principais)

\begin{tabular}{|l|l|l|}
\hline Processo Verbal & Processo & Processo existencial \\
Comportamental & $\begin{array}{l}\text { manifestações } \\
\text { exteriores de estados } \\
\text { psicológicos }\end{array}$ & $\begin{array}{l}\text { manifestações do que } \\
\text { existe e do acontece }\end{array}$ \\
\hline falar, dizer & comportar-se & haver; existir \\
\hline
\end{tabular}

Figura 9. Esquema dos Processos e Categorias Gramaticais (secundários)

As figuras 7, 8 e 9 nos ajudam a visualizar melhor os elementos da oração e o processo de relação entre eles. Podemos perceber que a metafunção ideacional representa os eventos das orações em termos de fazer, sentir ou ser, entre outros, por meio do sistema da Transitividade, que envolve: (a) Participante; (b) Processo; e (c) Circunstância. 
Assim, a figura 7 descreve a oração como um todo, no caso dos CVs, há uma predominância de orações onde o grupo pronominal pode ser descrito como sendo da primeira pessoa do singular, porém, algumas vezes, há o recurso do uso da terceira pessoa do singular com a omissão do sujeito. Contudo, apesar de compreender a importância dos demais elementos, o foco da análise se dá no elemento verbal. A figura 8 deixa claro que grande parte dos verbos que ocorrem nos CVS fazem parte da categoria gramatical principal, basta observar a lista de verbos apresentada nos exemplos da figura 8. Todos os verbos listados pelo WordSmith foram classificados apenas nessa figura e não há incidência de verbos do CV na categoria secundária, apresentada na figura 9. Os verbos listados na figura 9 não ocorrem nos CVs do corpus analisado.

Depois de uma boa limpeza, a lista produzida pelo WordSmith apresentou uma lista dos verbos mais comuns (com mais ocorrências) do registro CVs. Os verbos ocorreram em tempos verbais diferentes, porém em sua maioria o pretérito perfeito e o presente simples foram os que mais apresentaram incidência. A lista final dos verbos com maior ocorrência aparece na figura 10. 
Verbos que mais ocorrem em Currículos

POSSUIR, GRADUAR, TRABALHAR, ADQUIRIR, VALORIZAR, TER, SER, PRETENDER, CAPACITAR, MOTIVAR, INSPIRAR, REALIZAR, QUERER, GOSTAR, PROCURAR, APROVAR

Figura 10. Os verbos com mais ocorrências em CVs

Os verbos mais frequentes nos CVs são em sua maioria de processo material, mental e relacional. Isso quer dizer que os CVs são formados por orações que representam o indivíduo (ator e experienciador) e sua experiência (meta e circunstância). Ao observar a figura 11 percebemos que os quatro verbos principais usados pelo autor nos CVs são todos relacionados ao processo material e, portanto, derivam da consciência e da percepção externa de observar os outros e ver o que eles fazem e de nos observar e ver o que fazemos. Diferente do que fazemos ao analisar o verbo e seus complementos nas análises linguísticas tradicionais, na LSF analisamos a oração como um todo e vemos os verbos e esse todo como um processo onde há um ou mais participantes e uma circunstância. No caso dos CVs, esse processo, já descrito na metodologia, é o elemento central da configuração da oração, ele é representado pelo verbo e indica a experiência do ator que vai se desdobrando através do tempo.

Os processos, segundo Fuzer e Cabral (2014, p.41), representam eventos que constituem experiências, 
atividades humanas realizadas no mundo; representam aspectos do mundo físico, mental e social. Para as autoras, como os processos são realizados tipicamente por verbos, a ideia de mudança perpassa a noção de processo. Para exemplificar essa ideia, apresentamos a figura 11 com o resultado estatístico dos quatro verbos com maior ocorrência nos CVs.

\begin{tabular}{|c|c|c|c|c|c|}
\hline A & B & C & D & E & F \\
\hline WORD & FREQ. & $\%$ & TEXTS & $\%$ & LEMMAS \\
\hline POSSUIR & 635 & 7.51 & 340 & 95 & \\
\hline GRADUAR & 121 & & 286 & 86.6 & \\
\hline TRABALHAR & 99 & & 44 & 11 & \\
\hline TER & 213 & & 156 & 48 & \\
\hline
\end{tabular}

Figura 11. A frequência dos quatro verbos com maior ocorrência (WordSmith)

Nos quatrocentos CVs compilados para esse corpus, o verbo possuir apareceu 635 vezes em 340 CVs. A maioria dessas ocorrências foi no tempo presente do indicativo e na terceira pessoa do singular, como em: ele possui graduação em física, ou possui experiência em gerenciamento de equipes. Nesse caso, o verbo "possui" usado na terceira pessoa do singular refere-se na verdade ao EU ator e escritor do CV. O fato do autor falar de si mesmo na terceira pessoa representa uma tentativa de se distanciar do objeto sendo promovido, ou seja, a autopromoção fica camuflada no verbo, como se 
esse indivíduo cheio de qualidades e possuidor de tantas coisas, fosse um outro e não o próprio EU. Os quatro verbos apresentados na tabela 11 podem ser analisados como sendo de natureza material, pois representam a experiência externa (ações e eventos), como estudar, trabalhar, fazer e acontecer. Objetivou-se analisar especificamente o uso da primeira pessoa do singular (EU) com base na teoria do Sistema de Transitividade da Linguística Sistêmico-Funcional. Descobrimos que na verdade essa primeira pessoa é representada pela terceira pessoa, mas que não perde o sentido de ser o próprio autor do currículo, que para se distanciar do seu produto, ele mesmo, recorre a estratégia de referir-se a si mesmo através da personificação de uma terceira pessoa, que é ele mesmo. A função ideacional foi escolhida como o recurso linguístico para a análise da relação entre o escritor do CV e seu produto, ou seja, ele mesmo. As considerações e as conclusões relacionadas ao estudo são apresentadas na próxima seção.

\section{CONSIDERAÇÕES FINAIS}

Analisamos o contexto discursivo do currículo através dos pressupostos teóricos da Linguística Sistêmico Funcional e da Linguística de Corpus. Dentre as diversas possibilidades de investigação, a metafunção ideacional foi escolhida 
como o recurso linguístico para a análise da relação entre o escritor do CV e seu produto, ou seja, ele mesmo. Descobriuse que determinados padrões de progressão temática fazem parte da caracterização de alguns registros, como no caso do CV, o conteúdo experiencial dos seus temas está focado no indivíduo portador de inúmeras experiências e qualificações adquiridas através do tempo com estudo e trabalho. Por meio das escolhas léxico-gramaticais e da interação entre o escritor e o marketing dele mesmo como um produto. Concluiu-se, portanto, que todo o foco do registro CV está concentrado nos pronomes de primeira pessoa e nos verbos (características léxico-gramaticais) que sempre remetem ao autor do CV e a sua experiência. Essa centralização no remetente, sua experiência no mercado de trabalho, suas experiências intelectuais e escolares estão intimamente ligadas ao objetivo desse registro: fazer a promoção pessoal do candidato a uma vaga no mercado de trabalho.

Depois de investigarmos como o escritor se nomeia e come ele é nomeado, concluímos que o autor do CV aparece muitas vezes como o ator do discurso, desempenhando um papel ativo e esse papel poderá ser algumas vezes mitigado pelo uso da terceira pessoa, identificada com verbos passivos, como uma tentativa de falar de si mesmo, mas como se você 
fosse um ser distante, impessoal, uma outra pessoa, mas sem nunca perder o intuito de se promover. A ferramenta da LSF ao analisar os verbos nos ajudou a desenhar o perfil desse ator como um indivíduo proativo e trabalhador. Os resultados mostram que cada um dos contextos discursivos presentes nos CVs possuem uma função própria e que tais funções podem ser observadas através das escolhas verbais dos CVs. Concluiu-se que é possível usar a primeira ou a terceira pessoa do singular para representar esse EU. Essa investigação abre portas para pesquisas futuras que tenham interesse em investigar e discutir como os significados associados às práticas sociais e discursivas podem ser construídos e como eles se diferem quando são veiculados em comunidades discursivas de culturas diferentes, como pode vir a ser o caso de uma investigação como essa, mas que use um corpus de CVs traduzidos ou de CVs bilíngues, destinados a públicos de culturas diferentes.

\section{REFERÊNCIAS}

BATHIA, V.K. (1993). Analyzing genre: Language using in professional Settings. New York: Longman.

BERBER SARDINHA, T.B. (2004). Linguística de Corpus. Barueri: Manole. BERBER SARDINHA, T.B. (2009). Pesquisa em Linguística de Corpus com o WordSmith Tools. Campinas, São Paulo: Mercado de Letras.

DAVIS, B.D.; MUIR, C. (2003). Resumé Writing and the Minority Student. Business Communication Quarterly, Vol.69. p.435-439. 
FURKA, I. (2008). The Curriculum Vitae and the Motivational Letter: A Rethorical and Cultural Analysis. WoPaL, Vol.2. p.18-37.

FUZER, C.; CABRAL, S.R.S. (2014). Introdução à Gramática Sistêmico Funcional em Língua Portuguesa. Campinas, SP: Mercado de Letras.

HALLIDAY, M. A. K. A. (1970). Course in Spoken English: Intonation. Oxford: O.U.P.

HALLIDAY, M. A. K.; MARTIN, J. R. (1993). Writing science: literacy and discursive power. Pittsburgh: University of Pittsburgh Press.

HALLIDAY, M. A. K. (1994). An introduction to functional grammar. London: E. Arnold.

HALLIDAY, M. A. K.; MATTHIESSEN, C. (2004). An Introduction to Functional Grammar. London: Hodder Education.

IKEDA, S. N.; SILVA, L.B.G.C.; SAPARAS, M. (2015). As metáforas e a persuasão em editorial de jornal: um enfoque da Linguística Sistêmicofuncional. Veredas Online - atemática. Vol.19, n2. Juiz de Fora. p.225-247. SCOTT, M. (2012). Wordsmith Tools. Oxford University Press.

SEELY, J. (2005). Oxford Guide to Effective Writing and Speaking. Oxford: Oxford university press.

SWALES, J.M. (1990). Genre analysis: English in Academic and Research Settings. Cambridge: Cambridge University Press.

TEUBERT, W.; CERMÁKOVÁ, A. (2007). Corpus Linguistics: A short Introduction. London: Continuum.

THOMPSON, G. (2004). Introducing Functional Grammar. London: Arnold.

Simone Vieira Resende é doutoranda em Linguística Aplicada e Estudo da Linguagem na PUC São Paulo (2015, orientada pelo Prof. Dr. Tony Berber Sardinha) com pesquisa na área de Linguística de Corpus, Análise Multidimensional e Tradução. Possui mestrado em Linguística pela Universidade do Estado do Rio de Janeiro - UERJ (2011). É pós-graduada em Linguística Aplicada: Inglês como Língua Estrangeira pela Universidade do Estado do Rio de Janeiro (UERJ - 2008). É graduada em Letras Português e Literatura da Língua 
Portuguesa e Letras Português/Inglês pelo Centro Universitário Plínio Leite (2003). Tem experiência na área de Linguística, com ênfase em Linguística Aplicada ao Ensino de Língua Inglesa, Linguística de Corpus e Análise Multidimensional, atuando principalmente nos seguintes temas: Linguística de Corpus, Tradução, Tradução Técnica, Terminologia, Ensino-aprendizagem de língua estrangeira, Ensinoaprendizagem de tradução e análise multidimensional.

Recebido em 05 de outubro de 2016. Aprovado em 12 de novembro de 2016. 